\title{
Ensinar e educar em instituições especializadas: abordagem clínica dos vínculos de equipe ${ }^{1}$
}

\author{
Teaching and learning at specialized institutions: \\ a clinical view of team ties
}

Jean-Pierre PINEL²

Resumo

Este artigo aborda a exploração de processos psíquicos mobilizados quando equipes instituídas encontram-se em situação de articular uma missão de educação especializada e de ensino adaptado. Tentará mostrar que a análise clínica de práticas de equipe permite uma melhor compreensão das fontes inconscientes dos entraves à cooperação, que tomam a forma de antagonismos radicais a partir do momento em que a psicopatologia dos vínculos prevalece. Os argumentos, situados na perspectiva de uma clínica psicanalítica dos vínculos e da intersubjetividade, basear-se-ão em experiências grupais.

Palavras-chave: intersujetividade; práticas psicológicas em instituições; psicanálise; vínculos.

\begin{abstract}
This text focuses on the exploring psychic processes activated when instituted teams are set to articulate a mission for specialized education and adapted teaching. It attempts to show that a "clinical analysis of teamwork" provides a better understanding of the unconscious sources that impair cooperation, and which turns into radical antagonisms from the moment the psychopathology of links prevails. My arguments, under the links and of intersubjectivity perspective from the psychoanalytic clinic will be based on group experiences.
\end{abstract}

Key words: intersubjectivity; institutional psychological practices; psychoanalysis; bonding.

Muitas instituições especializadas têm como particularidade reunir profissionais de formações diversas, cuja missão comum consiste em promulgar uma educação ou uma reeducação destinada a crianças ou adolescentes em dificuldade psicológica e social. Essas instituições, que podem inscrever-se no setor social ("casas de criança" de caráter social) ou médico-social (institutos de reeducação), funcionam em sistema de internato ou semi-internato e reúnem, entre outros, professores e educadores especializados. Agenciamentos administrativos e diferentes modos de contratação organizam a participação dos professores em uma missão global do estabelecimento. Essas diferenças de contrato podem colorir as relações, mas não estruturam, por si mesmas, os tipos de vínculo e de cooperação estabelecidos entre os profissionais.

Essas equipes instituídas constituem grupos de trabalho (Bion,1961) vetorizados por um objetivo

$\boldsymbol{\nabla} \mathbf{\nabla} \boldsymbol{\nabla}$

1 Trabalho traduzido para o português por Maria Carolina Yasbek Gonçalves da Silva, Mestre em Psicologia pela Université de Paris X - Nanterre.

2 Professeur Doutor, Université de Paris XIII. Campus de Villetaneuse, 99, Av. Jean-Baptiste Clément, 93430 Villetaneuse, France. 
comum, a saber: cada profissional participa com suas especificidades e em colaboração com os membros da equipe de atendimento das crianças acolhidas. Esse objetivo raramente consegue atingir o estatuto de representação-objetivo compartilhada, sendo o objetivo manifesto de cooperação freqüentemente desmentido pela clínica institucional. As discordâncias, as incompatibilidades (Fustier, 1999) e a desvinculação parecem reger os modos de relação estabelecidos entre educadores e professores especializados. Em outras palavras, os obstáculos ao estabelecimento de uma aliança de trabalho parecem prevalecer a maior parte do tempo.

Tal constatação abre-se sobre uma série de questões intrincadas: que modelos de compreensão permitem dar conta dessas incompatibilidades? Quais são as fontes de discordância? O que as organiza? Enfim: em quais condições e apoiando-se em quais dispositivos pode-se favorecer uma reorganização desses modos de funcionamento? As hipóteses aqui defendidas podem ser formuladas da seguinte maneira:

- O material oriundo dos grupos "de análise clínica das práticas de equipe" permite mostrar que os obstáculos à cooperação entre educador e professor especializado podem pender na direção de uma psicopatologia durável dos vínculos.

- Essa psicopatologia, em período agudo, se mostra resistente à elaboração, uma vez que se desenvolve simultaneamente nos três registros de funcionamento psíquico (intra, inter e transubjetivo) diferenciados por Puget (1989).

- A psicopatologia dos vínculos se traduz por posições de retração identitária clivadas que se enraízam no originário institucional de cada uma das profissões presentes.

- A superposição desses mecanismos favorece o estabelecimento de conivências e alianças inconscientes entre os profissionais e os sujeitos acolhidos, imobilizando todo o conjunto numa situação violenta.

\section{Os grupos de análise clínica em instituição especializada: apresentação do dispositivo}

Este dispositivo responde a uma demanda institucional que, como bem mostrou Rouchy (1998), apresenta sempre uma ambigüidade entre uma expectativa de formação pessoal, de regulação de equipe e de intervenção institucional. Ainda que a resposta seja formulada em termos de formação institucional - sendo objeto de uma convenção e inscrevendo-se assim a título de formação permanente -, não se trata de maneira alguma nem de uma contribuição teórica, nem de uma aplicação direta de um modelo de tipo Balint. As condições institucionais não se prestam a tal dispositivo.

Assim sendo, propus progressivamente intitular esse tipo de formação de "grupo de análise clínica das práticas de equipe", cuja instrução de trabalho é atualmente formulada da seguinte maneira: "Trata-se de um tempo de trabalho institucional que reúne o conjunto dos profissionais inscritos em um processo de formação. A duração das sessões é de uma hora e meia, a freqüência é mensal (ou às vezes bimensal). 0 objetivo dessas sessões de trabalho é elaborar as interferências que se estabelecem entre as problemáticas dos sujeitos acolhidos e os modos de funcionamento da equipe. Por meio do estudo de caso, ou mesmo de situações, a equipe analisará o que está em jogo entre os sujeitos acolhidos, os grupos e as equipes instituídas. Os assuntos discutidos aqui se limitam aos aspectos profissionais das relações. Não serão tomadas decisões grupais durante as sessões e aquilo que for conversado não poderá ser usado fora das sessões para fins de ataques pessoais ou grupais".

Essas instruções revelam, logo de entrada, a problemática dos vínculos como objeto de trabalho original, mantendo uma parte irresoluta quanto às localizações e fontes dos disfuncionamentos. Em outras palavras, esse dispositivo indica explicitamente que terá necessariamente um caráter de intervenção clínica junto a esse grupo específico, que constitui a equipe, sem subestimar o impacto da patologia sobre a economia psíquica dos profissionais.

\section{A equipe instituída, um grupo singular}

A equipe em instituição social ou médico-social é um grupo organizado ligado por uma tarefa comum definida pela instituição. Trata-se, assim, de um conjunto intersubjetivo em estado de tensão entre três pólos: 0 grupo, a instituição e a organização.

De um lado, a equipe consitui um pólo grupal por ser objeto de representação e de investimento 
pulsional para cada um dos profissionais, mas também por seu campo intersubjetivo, sustentando vínculos interpessoais. O pólo grupal constitui uma matriz e um conjunto supra-individual (Neri, 1995), no qual se formam mecanismos específicos como os que foram descritos por Bion, em termos de grupo de base. O investimento do grupo como objeto é a representação de uma vivência inconsciente comum de crença na existência de uma entidade fantasmática própria, que transcende a soma dos indivíduos em grupo e que resulta da ressonância fantasmática (Decobert, 1990).

Por outro lado, a equipe inscreve-se em um enquadre institucional que constitui uma formação que sustenta e contém, oferecendo um ideal, uma missão, uma tarefa primária assim como representações e objetivos comuns. O pólo institucional coloca limites, regras simbólicas e modelos de representação, modelando uma forma de mentalidade e legitimando certos tipos de práticas. Os modelos instituídos transparecem principalmente em rituais, repetições não mentalizadas e enunciados indiscutíveis, tais como"aqui fazemos dessa forma". Nesse registro, uma parte da prática e de suas respectivas representações não podem ser verdadeiramente pensadas. Algo que é irrepresentável institucionalmente conduz a que uma parte do material psíquico passe despercebido no intuito de preservar um aspecto renegado ou de foraclusão presente no enquadramento ou na fundação institucional. Os pactos denegatórios e as negações comuns (Kaës, 1989) formam um sistema de alianças inconscientes destinado a lutar contra os riscos de desvinculação e a "remendar" a negatividade.

Enfim, o pólo organizacional dá uma atribuição a cada um dos membros da equipe, definindo lugares e funções relativas, determinando papéis e vínculos obrigatórios de trabalho. Ele fixa os dispositivos e contribui para manter a continuidade do enquadramento e das práticas. O pólo organizacional sustenta o grupo de trabalho definido por Bion (1961).

Ao mesmo tempo em que esses três pólos, sempre em tensão, constituem os eixos de uma triangulação potencial, são habitados por movimentos de desvinculação que contribuirão para destruir as articulações. De fato, a clínica evidencia que cada um desses pólos pode prevalecer sobre os outros dois. Quando o pólo grupal domina, a equipe funciona de modo coeso. Tomados por uma ilusão grupal (Anzieu, 1971) durável e massiva, os profissionais tenderão a libertar-se dos limites e regras diferenciadoras. Por outro lado, quando o pólo institucional governa a equipe, todo o conjunto é sujeito a um ideal grandioso, ocasionando assim um funcionamento ideológico de fechamento e, algumas vezes, um fanatismo de contorno sectário, quando aliado a processos e modos de organização profundamente alienantes, como os descritos por Diet (1998). A prevalência do pólo organizacional é caracterizada por desvios burocráticos. Nessa configuração, o sentido da tarefa primária se desfaz e os profissionais perdem toda esperança. $O$ desmantelamento da ilusão grupal e a racionalização radical das práticas destroem os significados da ação educativa ou reeducativa.

Assim, a equipe é mais um ideal de funcionamento - um mito que vetoriza um modelo de vínculos imaginários - do que uma verdadeira estrutura que sustenta alianças de trabalho e de cooperação. Além do mais, certas características institucionais aumentarão os riscos de desvinculação ao constituírem grupos com destinos aleatórios.

\section{A equipe educativa em instituição especiali- zada: uma aliança de trabalho improvável}

Fustier (1998) propôs ligar as incompatibilidades que se estabelecem entre profissionais de profissões diferentes a uma "regressão" no sentido de uma identidade profissional a priori (grifo do autor). A intensificação dos conflitos interprofissionais se alimentaria no desejo narcísico da cada profissional de conservar, ou mesmo de aumentar, seu território simbólico. A radicalização dos antagonismos resultaria de uma perda de satisfação, de um sentimento de falha com relação à prática; em outras palavras, de implosão do processo pedagógico e educativo. Sendo assim, a focalização sobre as identidades profissionais teria o sentido de uma busca de emblemas, visando preencher a falta. Para Fustier, esses conflitos têm como fonte uma crise mais fundamental, que atravessa o conjunto das instituições do setor da infância inadaptada e que ele relaciona a uma perda do sagrado ou da transcendência, quer dizer, a um desmantelamento dos fundamentos imaginários que organizam esses estabelecimentos relativos à instituição da infância inadaptada. 
A análise proposta por Fustier (1999) articula três níveis de desvinculação em constante intricação na clínica: um nível interpessoal (o conflito interprofissional), um nível intrapessoal (a busca narcísica de cada profissional que visa preencher uma ferida ou uma desilusão) e um nível transpessoal, significando aqui institucional como desmantelamento dos fundamentos imaginários da instituição "infância inadaptada". É preciso pontuar que a ordem com a qual essa análise é desenvolvida coincide com o modelo metodológico de análise dos fenômenos intercríticos propostos por Guillaumin (1979). Esse enquadre metodológico permite diferenciar e articular o material que, na prática clínica, surge de maneira abundante e caótica.

Um estudo aprofundado do material proveniente de grupos clínicos permite, no entanto, prolongar essa análise e observar certos processos inconscientes implicados na repetição dessas incompatibilidades. De fato, ao reunir professores especializados e educadores, os estabelecimentos ligados à instituição da infância inadaptada confrontam os profissionais a um encontro marcado pelo selo da inquietante estranheza (Freud, 1919/1986). Mesmo se essas duas profissões têm por finalidade a ajuda educacional e o desenvolvimento infantil, elas se constituiriam a partir de duas linhagens institucionais distintas.

As pesquisas centradas na história da infância inadaptada ${ }^{3}$ mostraram nitidamente que essa instituição fundou-se em oposição ao modelo adotado pelo Ministério da Educação. Os sistemas de formação, as referências teóricas, os métodos de trabalho, os modelos identificatórios, as filiações, os ideais e os mitos fundadores da infância inadaptada foram forjados fora do Ministério da Educação. Suas fontes essenciais são a militância social e/ou política e as ciências sociais e humanas. A profissão de educador especializado, pivô da infância inadaptada, apresenta, assim, a particularidade de ter-se constituído à margem ou mesmo em ruptura com os modelos tradicionais e dominantes da educação comum.

Em outras palavras - e este ponto é capital -, as instituições especializadas que possuem uma escolaridade interna devem fazer coexistir e colaborar diferentes profissionais, cujas culturas profissionais são, ao menos originariamente, divergentes. Mais do que simples diferenças estabelecidas sobre um fundo comum, trata-se de uma oposição fundadora, modelo/contra-modelo: a infância inadaptada encarrega-se de tratar, em um plano imaginário, os fracassos, as falhas e os excluídos da educação e da aprendizagem convencionais.

A profissão de professor especializado, destinada precisamente a articular o que não parecia tão desconexo, é, no entanto, o produto de um só modelo. A formação desses profissionais efetua-se em um enquadramento, o do Ministério da Educação. O lugar dos profissionais "psi" geralmente mais distantes dessas equipes de profissionais não poderá ser abordado frontalmente neste artigo porque essa questão precisaria ser examinada de uma maneira mais específica que não permite ultrapassar os antagonismos forjados durante as formações iniciais.

Certos elementos essenciais formarão marcas distintivas, saliências nos fundamentos de cada identidade profissional e ressurgirão em momentos de crise, ajudando a acentuar antagonismos entre ensinar e educar. Essas saliências constituir-se-ão como formações paradoxais. Combinando-se a identificações narcísicas, elas imobilizam o estabelecimento de alianças de trabalho. Quatro traços se destacam regularmente nos grupos de análise clínica: as oposições criança/aluno, global/parcial, grupo/indivíduo, projeto/ programa. Formularei aqui a hipótese que tais antagonismos podem ser analisados como sinal de uma implosão da dialética continente/conteúdo. As disjunções e os paradoxos dessa situação formam pólos de atração onde se abrigam incompatibilidades entre as identidades e as práticas profissionais em momentos de isolamento identitário massivo.

Em outras palavras, a redução da dialética continente/conteúdo em um dos dois termos gerará uma série de incompatibilidades acopladas. Os antagonismos evidenciam uma discordância entre os vertex (Bion,1961), uma incompatibilidade de ponto de vista, pré-orientando as práticas e entravando as trocas entre os protagonistas. Tudo se passa como se os profissionais

Q

3 Os ataques contra os vínculos e as alianças inconscientes. Três breves exemplos clínicos ilustrarão a profundidade dos antagonismos de fundo e os efeitos do impasse engendrado. Eles provêm de grupos de análise clínica diferentes. 
não conseguissem mais, em momentos de crise, constituir as crianças acolhidas como objetos de investimento comuns, cujas problemáticas seriam semeIhantes, intercomunicáveis.

As disjunções criança/aluno, global/parcial, grupo/indivíduo, projeto/programa encontram-se associadas a um imaginário das práticas originárias, emblemáticas, de cada uma das profissões. De um lado o professor, único mestre de sua classe, abre a criança ao saber e transmite um conteúdo, sem a intervenção de quem quer que seja. Essa relação dual, sem terceiros, que pode evidentemente favorecer uma organização fantasmática centrada na onipotência e na confusão, contribui para a exacerbação de movimentos violentos do registro do "ou ele ou eu" analisado por Bergeret (1984).

A prática pedagógica tende a constituir a criança como um objeto parcial ao reduzir o sujeito a uma única função claramente identificável, com designações como aprendiz, muito em voga atualmente. Essa cisão do sujeito reaparece de maneira recorrente em denegações tais como:"nós, os professores, não estamos aqui para educar os alunos, isto é tarefa para os pais e para os educadores". Enfim, as referências pedagógicas e os dispositivos que enquadram a prática do professor especializado são predeterminados pelo Ministério da Educação (programas, métodos, níveis, avaliações), vale dizer, fora do local do exercício profissional. As normas que guiam a prática do professor são então inevitavelmente heterogêneas em relação às normas da instituição que o acolhe. $O$ que pode ser tratado como uma distância diferenciadora, exercendo a função de conflitualidade criativa durante as fases de cooperação, vai tender em direção de um antagonismo radical nos períodos de crise.

Por outro lado, o educador especializado referese sobretudo a um modelo grupal, sustentado pela referência à equipe educativa ${ }^{4}$. Concebida como um pólo identificador e contendor, a equipe educativa é fortemente investida. Ela exerce uma pluralidade de funções psíquicas conscientes e inconscientes. Lugar de elaboração dos projetos e dos métodos de intervenção,"porta-ideal" e espaço de depósito do negativo, ela é o cadinho onde se forjam as identidades profissionais e a cultura própria dos educadores. De fato, o educador especializado, formado inicialmente como um generalista (trata-se de um paradoxo fundador), forjará sua identidade profissional na relação com uma equipe e uma instituição concreta.

Paralelamente, a prática educativa inscreve-se em uma visão global junto a um objeto imaginário construído: a criança, que deve ser atendida e acompanhada de maneira contínua e total. Sendo assim, os vínculos que a criança teceu com sua família, e os que ela tentou estabelecer com seu professor, tenderão a ser recalcados, ou mesmo atacados. Esse modelo de educador identificado à mãe onipotente e dedicada foi profundamente analisado por Fustier (1987). Os fantasmas de apropriação, ou mesmo de rapto de crianças, que se associam a esse modelo ajudam a exacerbar os antagonismos. Sendo assim, a redução às identidades profissionais de origem é usada e imobilizada na fundação das duas instituições de afiliação dos profissionais.

\section{A angústia gerada pela inquietante:}

- Em um instituto de reeducação: os movimentos de transição entre os tempos de vida cotidiana e os tempos de classe acompanham-se de uma desorganização, que se traduz por uma excitação e uma violência massiva, afetando o grupo de crianças. As passagens ao ato acontecem em situações caracterizadas pela abstenção e mesmo indiferença da parte dos adultos. Cada profissional delega a outro subgrupo a missão de gerenciar esses tempos intermediários.

- Em uma "casa de crianças" de caráter social: durante o tempo de reunião de equipe, as crianças perambulam e exprimem uma vivência de perda de referência, de contenção e de limite por meio de atos de violência repetitivos. Nenhum acordo é encontrado para organizar a permanência dos adultos junto às crianças. Para os educadores, essas reuniões acontecem durante os períodos habitualmente destinados às atividades escolares, sob incumbência dos professores. O ponto de vista dos professores é outro na medida em

- O termo "equipe" pressupõe claramente a colaboração de profissionais situados em lugares, papéis e funções diferentes; mas o termo "equipe educativa" mostra-se ambíguo, visto que designa mais comumente um grupo fundado sobre ele mesmo, mais do que sobre a diferença. A familiaridade, ligada a uma proximidade potencial muito grande, é assim negada e encarcerada em uma série de clivagens que proíbem a interidentificação. 
que consideram estar diante de uma missão educativa que correria sob a responsabilidade dos educadores.

- Em um instituto de educação para pré-adolescentes: a professora é confrontada alternativamente com manifestações de violência incontrolável ou com a classe vazia. Os adolescentes organizam-se em torno de uma modalidade de funcionamento grupal de tipo ataque-fuga (Bion, 1961). Diante do sofrimento expresso por essa professora, os educadores não podem nem participar da elaboração da problemática subjacente, nem propor um dispositivo que favoreça o investimento, pelos jovens, do enquadre escolar. Do ponto de vista dos educadores, essa situação seria fruto de uma falha de formação ou mesmo da fragilidade pessoal da professora.

Esses três exemplos evidenciam que as incompatibilidades podem tornar-se agudas e mobilizar uma ferida narcísica massiva nos profissionais. Entretanto é conveniente aprofundar um pouco mais a análise. Pode-se formular a hipótese de que essas incompatibilidades têm relação com patologia dominante acolhida. Em outras palavras, as incompatibilidades testemunham a favor da possibilidade de influência da ressonância fantasmática e revelam a formação de alianças inconscientes (Pinel, 1996), costurando o funcionamento dos profissionais com a psicopatologia das crianças acolhidas. Proponho designar essas alianças com o termo de aliança psicopática.

De fato, nos três exemplos clínicos citados, vê-se que o modo de funcionamento dos profissionais associa-se ao recrudescimento das ações e a uma explosão de violência. Tudo se passa como se os profissionais favorecessem inconscientemente essas ações. Para dar conta dos processos mobilizados, apoiar-me-ei, por um lado, sobre o texto de Freud intitulado Personagens psicóticos em cena (1905/1984) e, por outro lado, sobre os trabalhos de Kaës $(1989,1992)$ centrados na questão das alianças inconscientes nos conjuntos intersubjetivos.

No artigo citado, Freud defende a hipótese de que o homem confrontado ao espetáculo de uma transgressão experimenta um gozo ao identificar-se ao rebelde e à insurreição contra as instituições, quer dizer, contra os limites e proibições que se encontram na base da cultura. Esse gozo é normalmente objeto de uma resistência ou de um contra-investimento que toma a forma de uma aversão, mas pode, em certas condições, manifestar-se diretamente.

As análises propostas por Kaës $(1989,1992)$ nos permitem compreender as condições de suspensão do contra-investimento, partindo da conivência do profissional com o agir violento. De fato, esse autor define a aliança inconsciente como uma formação psíquica intersubjetiva construída pelos sujeitos de um vínculo para reforçar certos processos, certas funções ou certas estruturas das quais se beneficiam. A aliança inconsciente implica a idéia de uma obrigação, de uma submissão ou de uma alienação. É uma formação psíquica de dupla face, que satisfaz certos aspectos pessoais e permite manter o vínculo. No que diz respeito particularmente à economia da aliança psicopática, nota-se que se exerce em uma destrutividade direcionada a outrem. Estabelece-se uma coalizão mais ou menos aberta e consciente entre um (dos) ator(es) e um (dos) cúmplice(s) mudo(s) contra uma vítima que sofre a ação violenta.

A vítima reduzida ao estatuto de objeto parcial submisso à violência de uma influência totalitária é negada em sua subjetividade. A aliança psicopática supõe a presença de uma testemunha passiva ou ativamente erigida à função de cúmplice. A constituição de um trio - o agente, o cúmplice e a vítima - permite satisfazer as pulsões destrutivas de cada um e fechar os espaços psíquicos ao manter uma negação comum. 0 modo de funcionamento, não destituído de perversão, é assim selado na cumplicidade da testemunha passiva. O conjunto se mantém por meio de uma interatividade na qual cada um é designado para um funcionamento fixo. No que diz respeito às situações clínicas descritas anteriormente, pode-se destacar dois roteiros diferentes.

Nas duas primeiras situações, as formas violentas de agir são exercidas manifestamente por crianças contra outras crianças (em geral, aqueles que sofreram violências e maus tratos familiares) sob o olhar passivo dos professores e dos educadores. Com essas ações, as crianças tentam convocar a intervenção de uma função de terceira pessoa, mas não encontram nada mais do que passividade, o que as mantém nesse modo de funcionamento onipotente. A cumplicidade criança/adulto exerce-se, manifestamente, contra uma criança e, de maneira latente, contra os adultos do subgrupo adversário. A aliança psicopática permite, então, fazer das 
crianças uma espécie de "porta-agir"e demonstra uma negação da diferença de geração, como se os adultos sentissem satisfação em uma forma de delegação pulsional.

Na terceira situação, a coalizão entre educadores e adolescentes é tramada contra um adulto e inversa às posições generacionais. Os educadores respaldam, mesmo que indiretamente, o agir e a violência dos adolescentes ao desqualificar a professora especializada. Ao invés de apoiá-la, propondo um dispositivo que favoreça o investimento na escolarização, os educadores legitimam a passagem ao ato. Mais que uma abstenção passiva, eles atribuem ativamente a violência a uma falha da professora.

A partir dessas análises, pode-se pensar que, enquanto as alianças perversas (Eiguer, 1996) se baseiam essencialmente em uma negação comum da diferença entre os sexos, as alianças psicopáticas fundam-se em uma negação comum da diferença de gerações. Nota-se que a terceira situação combina a destruição do feminino à negação. A conivência visa não somente renegar a diferença de gerações, mas também destruir o feminino. Encontramo-nos, assim, muito perto de um fantasma originário em falta de figuração, na qual uma criança e um pai se completam a fim de destruir a imagem materna.

Nessas três situações, confrontamo-nos à encenação do fantasma Uma criança é espancada (Freud, 1919/1985). Sabendo que essas formas de agir engendram-se em uma série de transformações e reversões situadas sob o selo da incestualidade (Racamier, 1995), não somos aqui confrontados a uma tentativa desesperada de simbolizar a cena primitiva fundadora da instituição da infância inadaptada?

\section{Conclusão}

A ideologia dominante, sustentada pela maioria dos textos do setor da infância inadaptada, descreve uma situação de parceria e de rede interinstitucional. A clínica, porém, evidencia, principalmente em momentos de crise, que a cooperação intra-institucional é rara. Nesse contexto, os educadores e os professores especializados constituem-se dois subgrupos coesos e antagonistas. Cada um forma um conjunto fechado, indivisível e indiferenciado, no qual o outro é representado como um adversário. O unidirecionamento sobre as práticas, os modelos e as referências profissionais iniciais operam assim uma forma de isolamento sobre as identidades profissionais iniciais. Em outras palavras, as incompatibilidades e a ruptura das alianças interprofissionas associam-se a uma focalização dos profissionais sobre o originário de suas identificações e de suas identidades profissionais. Esse retorno de um originário bruto, não elaborado, associa-se a um enfraquecimento do intermediário, da dialética continente/conteúdo e a uma perda do sentido de uma tarefa comum. Em momentos críticos, a retroação em direção a pólos arcaicos ou massivamente ideologizados de cada identidade profissional faz ressurgir traços de clivagem fundadora, habitualmente recobertos - mais do que ultrapassados - por vínculos institucionais.

As incompatibilidades resultam assim de uma telescopia entre identificações inconciliáveis e antagonismos ligados às identidades profissionais. Isso quer dizer que o isolamento identitário resulta da falência da interidentificaçao, que se manifesta por uma passividade, um abandono mútuo diante da patologia dos sujeitos acolhidos na instituição. De fato, as clivagens e os antagonismos de fundo são alimentados e aprofundados pela doença e podem se fixar na formação e alianças psicopáticas que confirmam a patologia das crianças ou adolescentes acolhidos e, algumas vezes, abrem-se em uma verdadeira violência institucional.

Essas posições de isolamento e refração, bem como esses antagonismos radicais, têm suas raízes em uma falha do pólo institucional. A crise da instituição infância inadaptada revela-se na incapacidade atual de oferecer contendores simbólicos que sustentem significações comuns, de ser um "porta-ideal"e de sustentar vínculos vivos. Em períodos críticos, a falha contemporânea da instituição da infância inadaptada combinase a uma carência conjuntural do pólo organizacional que não fornece mais os dispositivos que permitiriam organizar as relações entre as funções de educação e de ensino.

As incompatibilidades são inscritas, de um lado, nos períodos de formação inicial desses profissionais, mas, por outro lado, cabe aos estabelecimentos especializados oferecer às equipes novos dispositivos de 
formação para que os profissionais possam reapropriar-se tanto dos limites quanto da questão da negatividade. Efetivamente, somente em uma elaboração constantemente vivificada pelo vínculo com a prática podem desconstruir-se discursos ideológicos que clivam e negam, discursos que são difundidos pelas formações iniciais dos profissionais. $O$ dispositivo de análise clínica das práticas de equipe parece-me representar um dispositivo capaz de sustentar esse movimento de retomada e de elaboração das negações e das ideologias próprias a formações operatórias ou tecnicistas que, muitas vezes, perderam o vínculo com a realidade das práticas em instituição.

\section{Referências}

Anzieu D. (1971). L'illusion groupale. Nouvelle Revue de Psychanalyse, 4. Paris: Gallimard.

Bergeret J. (1984). La violence fondamentale. Paris: Dunod.

Bion W. R. (1961). Recherches surles petits groupes. Paris: P.U.F. 197.

Decobert S. (1990). L'Objet-groupe. Gruppo. 6, Paris: Editions Apsygée.

Diet E. (1998). Management sectaire et psychosociologie. Connexions 17. Toulouse: Erès.

Eiguer A. (1996). Le pervers narcissique et son complice. Paris: Dunod, nelle Edition, 2000.

Freud S. (1984). Personnages psychopathiques à la scène. trad. fr. in Résultats, idées, problèmes. Paris: P.U.F. (Originalmente publicado em 1905/1906).

Freud S. (1985). Un enfant est battu. trad. fr. in Névroses, psychose et perversion. Paris: P.U.F. (Originalmente publicado em 1919).
Freud S. (1986). L'inquiétante étrangeté. trad. fr. in L'inquiétante étrangeté et autres essais, Paris, Gallimard. (Originalmente publicado em 1919).

Fustier P. (1987). L'infrastructure imaginaire des institutions, à propos de l'Enfance Inadaptée. In R. Kaës et al. (sous la dir. de), Institution et institutions. Paris: Dunod.

Fustier P. (1998). De la crise du sacré au projet institutionnel. Connexions, 71. Toulouse: Erès.

Fustier P. (1999). Le travail d'équipe en institution. Clinique de l'institution médico-sociale et psychiatrique. Paris: Dunod.

Guillaumin J. (1979). Pour une méthodologie générale des recherches sur les crises. In R. Kaës et al. (sous la dir. de), Crise rupture et dépassement. Paris: Dunod.

Kaës R. (1989). Le pacte dénégatif dans les ensembles intersubjectifs. In A. Missenard et al. (sous la dir de), Le négatif. Figures et modalités. Paris: Dunod.

Kaës R. (1992). Pactes dénégatifs et alliances inconscientes. Eléments de métapsychologie intersubjective. Gruppo, 8. Paris: Editions Apsygée.

Neri C. (1995). Le Groupe, manuel de psychanalyse de groupe. Paris: Dunod.

Pinel J.-P. (1996). La déliaison pathologique des liens institutionnels. In R. Kaës et al. (sous la dir.de), Souffrance et psychopathologie des liens institutionnels. Paris: Dunod.

Puget J. (1989). Groupe analytique et formation. Un espace psychique ou trois espacessont-ils superposés? Revue de psychothérapie psychanalytique de groupe, 13. Toulouse: Erès.

Racamier P.-C. (1995).L'incesteet l'incestuel. Paris: Les Éditions du Collège.

Rouchy J.-C. (1998). Problématique de l'intervention, Connexions. 71. Toulouse: Erès.

Recebido em: 7/8/2006

Aprovado em: 17/8/2006 